\title{
O PARADIGMA MECANICISTA DA MEDICINA OCIDENTAL MODERNA: UMA PERSPECTIVA ANTROPOLÓGICA
}

Marcos de Souza Queiroz *

QUEIROZ, M. de S. O paradigma mecanicista da medicina, ocidental moderna: uma perspectiva antropológica. Rev.Saúde públ., S.Paulo, 20:309-17, 1986.

\begin{abstract}
RESUMO: Objetivou-se analisar, sob um ponto de vista antropológico, o paradigma "mecanicista" dominante na medicina ocidental moderna. Faz-se comentário crítico sobre o positivismo que sustenta este paradigma. Foi mostrado também como ele desenvolveu-se historicamente a ponto de dominar a percepção médica sobre saúde, doença e terapêutica, e como essa percepção deixou modernamente de compreender um amplo espectro da realidade a que se propõe compreender. Foram analisados alguns sistemas médicos "populares" e "primitivos", mostrando como eles incorporam o social no campo da medicina. Enfatiza-se a necessidade da medicina ocidental modema recuperar o social e o cultural (como dimensōes que moldam inevitavelmente a doença, os tratamentos e a cura) para sair da crise em que se encontra. Nesse sentido, recorrer à história e aos sistemas médicos "populares"e "primitivos" tem o propósito de contribuir para isso.
\end{abstract}

UNITERMOS: Antropologia da medicina. Medicina tradicional. História da medicina.

A medicina científica ocidental sofreu um processo de expansão extraordinária a partir da segunđa guerra mundial, consolidando um modelo baseado numa sofisticação tecnológica sem precedentes. Esta sofisticação lhe permitiu uma sintonia ainda maior com o sistema produtivo na medida em que aumentou significativamente o seu poder de intervenção no corpo humano a fim de moldá-lo às necessidades da produção (Possas 26, 1981). Além disso, esta sofisticação tecnológica não se fez sem um investimento maciço de capital, o que colocou o campo médico como uma área onde se processa uma acumulação de capital das mais intensas (Donnangelo6, 1975).

No campo ideológico, esse período caracterizouse por um grande otimismo no poder da ciência e da tecnologia na resolução dos problemas sociais e humanos. Acreditava-se, por exemplo, que a erradicação e o controle da grande maioria das doenças dependia somente do fator tempo. Uma a uma elas seriam subjugadas ao poder da inteligência humana treinada pelo método científico. Mais recentemente, no entanto, esse otimismo começou a ceder lugar a uma percepção onde se configuram os limites da expansão e das possibilidades da ciência e da tecnologia na resoluçao de alguns dos mais importantes problemas humanos. Isso é particularmente verdadeiro no caso da medicina, onde se verifica uma crise profunda não só da sua prática como do seu saber.

Esse artigo tem por objetivo refletir tanto sobre a natureza dessa crise como sobre as saídas possíveis para ela. Para isso, pretende-se recorrer à história e à antropologia.

Antes de prosseguir nessa direção, no entanto, é necessário recorrer tanto ao conceito de paradigma, conforme a formulação de Kuhn ${ }^{16}$ (1975), para compreendermos o significado de crise no campo científico, como as posições epistemológicas que fundamentam a crítica que pretendemos empreen. der.

De acordo com Kuhn16, a "ciência normal" não teria por finalidade produzir conhecimento novo mas apenas concentrar suas investigaçōes no óbvio determinado pelo paradigma (um mapa que governa a percepção dos cientistas) dominante no campo científico. Assim, o desenvolvimento real da ciência (não apenas a expansão interna do paradigma) ocorre apenas em circunstâncias raras e especiais, quando o paradigma entra num estágio de crise profunda e quando um novo paradigma (que dê conta da reaiidade que não poderia ser compreendida pelo paradigma anterior) é proposto.

Embora não seja possível sumarizar a posição de vários epistemólogos de importância, entre eles Lakatos e Musgrave17 (1970) e Kuhn16 (1975), pode-se dizer sem exagero que tem havido uma contribuição substantiva dessa área para uma radical mudança na percepção que a ciência tem de si mesma.

A ciência, desde o período renascentista, tem sido concebida em termos do relacionamento isolado entre o pesquisador e a natureza, mediados pelo conhecimento ou pelo saber do pesquisador. Atual. mente, a perspectiva desses epistemólogos dá muito

\footnotetext{
* Do Núcleo de Estudos de Políticas Públicas da Universidade Estadual de Campinas - Caixa Postal 1170 - 13100 - Campinas, SP - Brasil.
} 
QUEIROZ, M. de S. O paradigma mecanicista da medicina ocidental moderna: uma perspectiva antropológica. Rev. Saúde públ., S.Paulo, 20: 309-17, 1986.

mais atenção a fatores tais como a comunidade científica a qual pertence o pesquisador, o conhecimento partilhado por essa comunidade e as correntes sociais econômicas e culturais mais amplas dentro da qual essa comunidade existe. Assim, a percepção de um mundo natural independente do mundo humano que o percebe, um pressuposto fundamental do positivismo passa a ser ingenua na medida em que não avalia a importância da estrutura perceptiva influenciada pela sociedade e pela cultura na dimensão e no sentido assumidos pelo mundo natural.

Tanto a sociologia como a antropologia social e cultural têm sido pródigas em demonstrações teóricas e empíricas de que conhecimento varia conforme o contexto social e só tem sentido dentro dele. Os aparelhos de apreensão da realidade são socialmente modelados, exigindo um processo de aprendizagem. Aprende-se a sentir, a ver, a ouvir, a classificar e a discernir sobre o mundo que nos circunda. Isso nos leva à conclusão de que o conhecimento é inevitavelmente parcial, uma vez que a realidade é infinita e os aparelhos de apreensão da realidade do ser humano são limitados pela biologia (objetivamente) e pela cultura (subjetivamente). Portanto, a sociologia e a antropologia social e cultural contribuiram decisivamente para mostrar que fatores imanentes (lógicos ou metodológicos) ao conhecimento não podem explicar isoladamente o seu desenvolvimento, que para tal exige a introdução de fatores sociais e culturais. Essa posição constitui um grande golpe ao positivismo que pretende ver no conhecimento um desenvolvimento contínuo, com base num desvendamento objetivo da natureza, e passivel de ser acumulado no tempo com o mesmo sentido. Tal positivismo, como ironizou Sartre 31 (1967), nada mais é do que a ilusão de se chegar à unidade acrescentando noves a 0,99 .

A crise da medicina ocidental moderna refere-se à crise de seu paradigma dominante, o qual se identifica inteiramente com o positivismo ao não reconhecer o papel da sociedade, da cultura, da comunidade científica e da própria história na determinação não só do objeto do conhecimento como da maneira de abordá-lo. Alguns autores têm denominado esse paradigma como "mecanicista" (uma denominação que adotaremos ao longo desse artigo) por pressupor que, da mesma forma que qualquer objeto natural, a saúde e a doença podem ser explicadas exclusivamente pela interação mecâ. nica das diferentes partes do organismo humano.

A ilusão histórica do positivismo não permite reconhecer que o vínculo de um campo de saber com o seu meio social e cultural é inevitável. No caso da medicina, a sua crise provém não desse fato mas do seu excessivo comprometimento com as forças sociais primárias mais imediatas do meio social em que atua. Portanto, o objetivo de constatar a inevitabilidade da influência social e cultural num determinado campo de saber é justamente 0 de encontrar meios que preservem uma certa autonomia a esse campo de saber de modo a permití-lo encontrar soluções criativas que não poderiam ser encontradas normalmente por outras instituições sociais.

A antropologia, principalmente através de Turner 32 (1967), tem mostrado a universalidade do fator desestruturante (anti-estrutural) das manifestações artísticas e científicas. Certamente esse autor se refere à imagem de uma ciência criativa que ocorre excepcionalmente quando o saber é realmente inovado e não à uma ciência normal como a descrita por Kuhn 16 (1975). Isso porque, quando a ciência ou a arte servem no sentido de manter o "status quo" social, elas tendem a se cristalizar num comportamento institucional ritualizado subjugados aos interesses sociais a que servem, referendando o "já sabido" e sem condições de propor soluções e conhecimentos novos. Já o desenvolvimento de uma independência relativa das forças sociais mais imediatas permite à ciência uma postura crítica que é imprescindível à produção (e não meramente reprodução de conhecimento).

Numa frase bastante significativa, Popper 25 (1970 : 58) caracterizou a produção de uma ciência real como implicando necessariamente "uma quebra da estrutura de nossas teorias, de nossas expectativas, de nossa experiência passada, de nossa linguagem". Ele quer dizer com isso que a produção de uma ciência real implica superar os condicionantes da história, da cultura e de nós mesmos. Realmente, a história registra que o esforço para superar os limites impostos pelos condicionantes sociais acompanha todas as grandes realizações da arte e da ciência.

Portanto, é possível dizer, sem contradição, que num certo momento, a medicina científica tornou-se hegemônica exatamente por se mostrar compativel com o "ethos" capitalista e, num outro momento, tornou-se inviável exatamente por se mostrar excessivamente comprometida com esse "ethos", perdendo assim a sua independência e autonomia, ainda que relativas, face ao sistema social em que atua. Na medida em que a sua funcionalidade ao sistema significa tornar-se insensível às causas reais de doenças (que muitas vezes residem na forma como a vida é organizada pela sociedade) $\mathrm{e}$ às soluções que implicariam em melhoria do nível de saúde de uma população, a medicina tem produzido serviços extremamente caros e ineficazes, dois sintomas principais de sua crise.

A questão não é, propriamente, descartar a medicina como algo totalmente indesejável, cujo 
único propósito seria promover, no bojo dos interesses da indústria farmacêutica e hospitalar e da profissão médica, a ideologia da sociedade industrial e burocrática. Essa postura tem sido encontrada no chamado movimento "anarquista-cultural" norte -americano, tendo em Illich14 (1975) o seu principal proponente. A questão é se a medicina pode realmente tornar-se inteiramente uma ciência verdadeira na concepção de Popper 25 (1970), conquistando para isso uma independência maior dos interesses mais imediatos do modo de produção a que serve. Essa pretenção implica, necessariamente, considerar que o objeto da medicina, o ser humano, é diferente do objeto das ciências naturais, e exige a consideração de aspectos subjetivos, simbólicos e sociais para a plena apreensão da realidade a que se propõe estudar.

Essa breve introdução no campo da filosofia da ciência serve como ponto de partida do problem? que será então estudado sob uma persperiva histórica e antropológica.

\section{Um Pouco Sobre a História da Medicina Cientifica Ocidental}

Entre os gregos antigos, os mitos de Hygéia (deusa da saúde) e Asclépius (deus da medicina) simbolizam dois aspectos importantes da medicina. Para os adeptos de Hygéia, saúde dependia primordialmente de como os homens governavam as suas vidas. Nesse caso, ao médico cabia descobrir como um indivíduo pode melhor se adaptar ao seu meio social e físico através de restrições comportamentais e dietéticas, uma vez que a cura viria sempre da natureza, e a doença, de um relacionamento inadequado com ela. Nesse sentido, doença im. plica desajuste, geralmente mediado por relacionamento social desequilibrado. Dai o caráter de culpa e vergonha que acompanhava as doenças durante o mundo antigo e medieval.

Já os seguidores de Asclépius acreditavam que o principal papel do médico é tratar a doença e corrigir as imperfeiçōes trazidas pela vida através de terapias mais "heróicas", sem se preocupar muito em encontrar um modo de vida particular ao paciente. A ênfase recaia, portanto, no aspecto sintomático e curativo da medicina. Platão (citado por Livingstone20 (1940), por exemplo, mostra ter sido um adepto de Asclépius, uma vez que ele criticava o cuidado e o controle excessivo com o corpo que o método de Hygéia muitas vezes acarretava, privando, assim, o individuo de "praticar o seu ofício se é pobre, e de se por a serviço do Estado se é rico".

Em teoria, a medicina Hypocrática foi uma síntese elaborada a partir dessas duas tendências, uma vez que ela se preocupa tanto com a doença individual e com os meios para curá-la como também com a manutenção da saúde dentro de um sistema ecológico em que fatores tais como o ar, a água e o alimento, o clima são vistos como relevantes para a manutenção do equilibrio biológico.

Durante a Idade Média, a medicina manteve como pressuposto o paradigma aristotélico da unidade orgânica dos seres vivos, sendo a doença a expressão de alterações globais do organismo em interação com o seu meio físico e social. Assim, acreditava-se que, do mesmo modo como os hu. mores e líquidos do organismo influenciam as virtudes do homem, suas virtudes influenciam os humores.

No século XVII, Descartes estabeleceu os métodos para se pensar o corpo humano como máquina. Assim como Galileu tinha mostrado que o método científico era capaz de providenciar uma interpretação mecânica do mundo físico, Descartes não via razão porque os mesmos princípios não podiam ser estendidos ao mundo das criaturas vivas. Assim, ele criou a dicotomia entre mente (uma concepção divina, fora do alcance da ciência) e corpo (um organismo imperfeito que obedece a leis mecânicas). Nesse esquema, a doença aparece como um distúrbio de um dos componentes da máquina humana passivel de ser reparado pela in. tervenção de uma medicina que detivesse o conhecimento das leis que operam essa máquina. 0 corpo humano perdia assim seu caráter divino, intocável. Pouco tempo depois, ocorreu uma demonstração ainda mais dramática da validade da postura mecanicista na descoberta de Harvey da circulação do sangue.

A partir da Revolução Industrial, verificou-se uma ruptura fundamental entre saúde e medicina, com uma hegemonia flagrante desta última. Essa ruptura veio acompanhada da ruptura entre corpo e mente, eu e outro, pessoa e contexto, relações econômicas e comunitárias dentro de um mundo em intenso processo de burocratização e desencanto. Esse processo permitiu cada vez menos situar a doença entre a biografia individual e o mundo social, fator esse que, no nosso entender, explica a impossibilidade da medicina científica, então emergente, compreender um número muito grande de doenças de atualidade.

Essa ruptura, ocorrida dentro do capitalismo modemo, aliou ao processo de divisão de trabalho e de burocratização, interesses econômicos irracionais. Conti5 (1972), nesse particular, conclui o seu trabatho afirmando que todos sabem ser possível curar muitas doenças crônicas pela diminuição de fatores tais como poluição, alienação no processo de trabalho ou condições de "stress" na vida urbana, mas este saber se torna inútil quando a orientação médica é conduzida pelo sistema produtivo a aumentar 
QUEIROZ, M. de S. O paradigma mecanicista da medicina ocidental moderna: uma perspectiva antropológica. Rev.Saúde públ., S.Paulo, 20: 309-17, 1986.

e não a diminuir a "competência produtiva" tanto individual como coletiva.

No século XIX, Pasteur e Koch pensaram ter provado de modo inquestionável que doenças podem ser produzidas pela introdução de um único agente específico (um germe virulento) num organismo até então sadio. Como salienta Landman 18 (1983: 140) a respeito,

"Do campo da infecção, a teoria da origem sspecifica das doenças difundiu-se a outras áreas da medicina pela demonstração em animais le experiência da produção de doenças através de lesões específicas, anatômicas, fisiológicas ou bioquímicas. Agentes microbiológicos, distúrbios metabólicos, deficiência ou aumento de hormônios, enzimas e vitaminas, e o estresse eram considerados agentes específicos na etiologia das doenças. $O$ conceito da desarmonia entre o paciente e o meio em que ele vive ficou obscuro e nebul jso quando comparado com a terminologid "precisa" e as explicaçōes "seguras" da moderna ciência médica".

A partir de Pasteur e Koch, portanto, a medicina pensou ter se tornado uma ciência natural que teria o poder de controlar todas as doenças pela descoberta de antídotos especificos às suas causas específicas, tendo o indivíduo e não a população como objeto de interesse.

A questão da saúde que, também no século XIX, teve desenvolvimento muito promissor na medicina social, concebida por filósofos sociais (tendo em Engels o seu expoente máximo) e cientistas médicos (tendo em Virchow o seu expoente máximo), foi relegada a um segundo plano, apesar da clareza com que esses autores demonstraram que as doenças provêm das condições sociais de trabalho e de vida em geral.

A reforma da profissão médica nos EUA, após o relatório Flexner ${ }^{11}$ (1910) consolida a hegemonia do paradigma mecanicista, ao mesmo tempo que consolida a formação de uma profissão médica com um grau sem paralelos de poder, riqueza e prestígio. A descoberta dos antibióticos a partir de 1930 e a sua comercialização depois de 1945 refletiram o auge desse paradigma, levando muitos a crerem que a resolução da maioria dos problemas de saúde deveria ocorrer no campo da quimioterapia.

Mais recentemente, no entanto, dois fatores fundamentais contribuiram decisivamente para abalar os alicerces do paradigma mecanicista. $O$ primeiro $e$ principal deles diz respeito à deficiência desse paradigma em conceptualizar os problemas modemos da saúde humana. O segundo, diz respeito aos custos crescentes que esse tipo de medicina acarreta, tornando-o incompativel com o ideal de democratiza. ção da oferta de serviços médicos, principalmente em países em desenvolvimento.

Uma importante obra a comprovar o primeiro desses fatores é a de McKeown21 (1979) que mostra muito bem que a grande melhoria nos niveis de saúde que a população ocidental sofreu nesses últimos séculos se deve em primeiro lugar à maior disponibilidade de alimentos; em segundo lugar, à salubridade do meio ambiente (principalmente a disponibilidade de água potável e de sistema de esgoto; em terceiro lugar, ao controle da natalidade. A medicina, nesse sentido, teve um papel muito menor do que se lhe atribui. Mesmo o controle das doenças infecciosas, diz o autor, resultou principalmente da modificação ta condição na qual elas ocorreram, e apenas secundariamente pela ação quimioterápica.

Reforça esse argumento a comprovação em vários paises de que a partir de um certo ponto, o aumento do nível da atividade médica numa sociedade não corresponde a um aumento do nivel de saúde da população como se deveria esperar (Ehrenreich 9 , 1978). O que se verifica de fato é que enquanto a alocação de recursos para a área médica na maioria dos países desenvolvidos tem se multiplicado a partir dos anos 50, os ganhos em saúde têm sido irrisórios, principalmente nas duas últimas décadas. Isso sem falar nas inúmeras doenças provocadas diretamente pela ação da intervenção médica, ou seja, as doenças iatrogênicas. Num excelente artigo sobre o assunto, Powles 27 (1980) afirma que um dos mais notáveis paradoxos na cultura médica repousa no contraste entre o entusiasmo associado com crescentes investimentos sociais na área médica e a realidada de retornos decrescentes na área da saúde.

Um outro ponto a abalar o paradigma mecanicista diz respeito à grande proporção de doenças degenerativas tais como câncer, doenças do coração, hipertensão arterial, doenças psiquiátricas entre outras, que não se mostram tratáveis pela intervenção tecnológica baseada no modelo unicausal de doenças. Muitos autores têm considerado não só essas doenças mas também as infecciosas como de múltipla causalidade, na qual corpo, mente e meio-ambiente (incluindo mas não limitado por microorganismos exógenos) interagem para produzir a doença ou para curá-la. Como Dubos 8 (1965) argumentou a esse respeito, o ser humano traz com ele a maior parte dos germes causadores de grande parte das doenças a maior parte do tempo. Essas doenças, no entanto, só se manifestam quando a resistência a elas diminui ou quando a suscetibiiidade a elas aumenta, o que remete necessariamente às condições sociais que as propiciam. 
QUEIROZ, M. de S. O paradigma mecanicista da medicina ocidental moderna: uma perspectiva antropológica. Rev.Saúde públ.. S.Paulo, $20: 309-17,1986$.

No que diz respeito aos custos crescentes de uma medicina baseada no hospital e na alta tecnologia, a sua presença hegemônica em países como o Brasil, cuja grande maioria populacional é sub-alimentada e possui escasso controle ambiental, é evidentemente muito mais irracional do que o mesmo fenòmeno num país rico. $\mathrm{O}$ aumento das taxas de mortalidade infantil em aproximadamente $70 \%$ entre 1960 e 1975 no Estado de São Yaulo, ao mesmo tempo em que se promovia o chamado "milagre econômico" e se consolidava um sistema nacional voltado para uma medicina individualizada, sintomática, curativa e de natureza essencialmente hospitalar, multiplicando com isso os gastos "per capita" com os cuidados médiens, é um ótimo exemplo da ineficácia desse sistema e da necessidade de se promover uma alternativa para ele (Bacha1, 1979, sobre mortalidade infantil em Sạo Paulo). No entanto, é importante salientar que a crise da medicina não se limita aos problemas do subdesenvolvimento, uma vez que ela está intensamente presente também entre os países desenvolvidos capitalistas e socialistas (ver, por exemplo, Navarro23,24, 1976 e 1977, que, numa perspectiva marxista, critica tanto a medicina capitalista como a medicina socialista existente na União Soviética).

Sob o ponto de vista do relacionamento médico - paciente, o desenvolvimento da medicina ocidental moderna tem sido vista como um processo pelo qual o paciente perde a sua integridade e consciência socral e cultural de si mesmo e se torna um objeto de manipulação. De acordo com Jewson 15 (1976), a perda dessa identidade ocorreu através de três estágios históricos.

O primeiro estágio, denominado "medicina ao lado da cama", foi dominante no Ocidente até o fim do século XVIII. Sua característica principal consistia em que o paciente se situava no centro do processo médico e era tratado em sua totalidade. Assim, os dados à disposição do médico eram subjetivos, e os sentimentos e sensações do paciente eram considerados muito importantes na avaliação de sua condição. A "medicina ao lado da cama" também adotava a suposição de que a doença resultava de um distúrbio no relacionamento do ser humano com seu meio físico e social. Portanto, o equilíbrio tanto com o meio ambiente como com o meio social era considerado fundamental na causação de doenças e na manutenção da saúde. No entanto, como apontou Jewson 15, esse tipo de medicina se caracteriza também pelo grande número de teorias conflitantes que lutavam entre si por uma hegemonia.

A "medicina hospitalar", o segundo estágio, veio como resultado da revolução industrial e do processo de urbanização a partir do século XVIII. Esse tıpó de medicina classificava estados patológicos, dentro de um sistema de doenças que pretendia ser objetivo, no qual o paciente se tomava meramente um caso. Em tal situação, a doença deixou de ser considerada um distúrbio envolvendo uma totalidade biológica inserida num contexto sócio-cultural. Ela passou a ser diagnosticada tendo em vista ex. clusivamente a correlação objetiva de sintomas, sendo considerado irrelevante $o$ registro dos sentimentos e das sensações subjetivas do paciente a respeito da sua doença. Para esse fim, desenvolveu-se uma variedade de instrumentos para o exame interno e externo do paciente. No entanto, a possivel eficácia da medicina desse tempo, como tem notado vários autores (Doyal7, 1979; Berliner ${ }^{2}$, 1982), era quase sempre produzida por efeito placebo. Sem usufruir de uma medicina objetivamente superior, o paciente deixa de ser dominante no relacionamento médico-paciente, passando a exercer um papel secundário no qual os principais protagonistas passaram a ser os médicos (agora formando uma classe profissional cada vez mais poderosa) e as doenças isoladas dos pacientes num processo de reificação.

Finalmente, a medicina de laboratório, o terceiro estágio, teve início em fins do século passado, em sintonia com uma intensificação sem precedentes do processo de industrialização e urbanização. No campo médico, a visão de mundo mecanicista, enfatizando uma intervenção terapêtica ativa no processo fisiológico humano, atingiu o seu apogeu. Nesse estágio, as doenças deixaram de ser interpretadas através da estrutura patológica, e passaram a sê-lo através da estrutura celular. Com o uso do método experimental, a medicina tornou-se uma ciência natural que transformou o paciente não apenas num caso clínico mas num objeto a ser manipulado.

Portanto, enquanto as novas doenças, males e causas de mortes passaram a ser cada vez mais relacionadas com as condições de trabalho e de vida num determinado contexto sócio-econômico $e$ cultural, a medicina concentrava a sua atenção cada vez mais intensamente em conceitos etiológicos unicausais, baseados na teoria dos germes. Assim, como salienta Berliner ${ }^{2}$ (1982), a medicina científica tornou-se uma racionalização para não se lidar com as causas verdadeiras das doenças num modo que pudesse ser disfuncional para o crescimento produtivo capitalista. Em grande medida essa conclusão pode também ser extrapolada para a medicina de países socialistas. Nesse sentido, a medicina ocidental moderna valida, reforça, legitima e reflete as normas produtivas, o que nem sempre coincide com as necessidades de saúde de uma população. Isso quer dizer que somente uma revolução econômica onde se socializam os meios de produção não é suficiente para que ocorra uma revolução nas idéias e na cultura. 
QUEIROZ, M. de S. O paradigma mecanicista da medicina ocidental moderna: uma perspectiva antropológica. Rev.Saúde públ., S.Paulo, 20:309-17, 1986.

\section{Os Sistemas Médicos "Populares" e "Primitivos". 'um enfoque antropológico}

Vimos que, historicamente, o desenvolvimento da medicina implicou em perda de uma visão unificadora do paciente, e deste com o seu meio ambiente físico e social. Essa perda começou a ocorrer com a revolução industrial, mas só atingiu a sua plenitude no século XX. Trata-se, portanto, de um fenômeno recente e sem similar dentro da história do ocidente. Trata-se também de um fenômeno sem similar quando confrontado com outros sistemas médicos não ocidentais como a Acupuntura, a medicina Ayurvédica ou ainda os sistemas médicos populares da África, Âsia ou América Latina. Em todos esses casos, por mais diferentes que sejam, tanto as concepções de doença e de saúde como os tratamentos e as formas de cura, é possivel verificar um denominador comum: o pressuposto de que a saúde $e$ a doença dependem do relacionamento tanto das diferentes partes do organismo entre si como deste com o seu contexto sócio-cultural.

$\mathrm{O}$ argumento sustentado por este artigo é que a medicina ocidental moderna necessita recuperar essa dimensão para sair da crise que a levou a seu paradigma dominante. $\hat{\mathbf{E}}$ importante salientar, contudo, que focalizar medicinas populares ocidentais ou não ocidentais não significa contrapô-las favoravelmente à medicina ocidental modema. Isso porque se trata de situações de diferente escala e de diferente configuração cultural do problema. O que se pretende é constatar que nesses sistemas médicos altemativos, sejam eles simples conhecimento popular não sistematizado ou sistemas médicos complexos, o fator social existe como componente fundamental, ao contrário do que ocorre com o paradigma dominante da medicina ocidental modema.

Dentro da própria medicina ocidental moderna, a incorporação do social no campo médico, embora configurando uma mudança radical de paradigma, não constitui propriamente uma possibilidade teórica nova. Como vimos, a dimensão social existe como componente fundamental para a medicina desde a medicina Hipocrática, tendo sido enfocada com rigor científico no século XIX. Em termos concretos, portanto, a recuperação do social pela medicina não seria tão somente uma questão epistemológica, mas inevitavelmente política.

Isso posto, estamos agora em condições de analisar os estudos antropológicos sobre medicinas "populares" e "primitivas".

A no $0_{3} a ̃ o$ de equilíbrio pode ser tomada como uma noção fundamental para a medicina de numerosas sociedades de tecnologia simples. $\mathrm{Na}$ América Latina, esta noção está presente no equilíbrio do homem com o seu meio natural (dentro da lógica do "quente e frio"), no equilíbrio do homem com o seu meio social (através da crença de que crises no relacionamento social provocam doenças) e no equilíbrio do homem com ele mesmo e com agentes sobrenaturais (através da crença de que crises emocionais ou influências sobrenaturais provocam doenças).

A lógica do "quente e frio" tem sido encontrada em praticamente toda a América Latina e consiste num sistema que classifica como quente ou frio certos elementos, principalmente alimentos e ervas medicinais, e atribui uma performance terapêutica diferencial desses elementos no corpo humano. Assim, doenças quentes devem ser tratadas com ervas medicinais e alimentos frios, e as doenças frias devem ser tratadas com ervas medicinais e alimentos quentes (Queiroz, 29,30, 1982, 1984).

A crença de que crises no relacionamento social provocam desequilibrios emocionais que levam a doenças está presente nas tão difundidas crenças em "mau-olhado", feitiço ou inveja. Basicamente, essas crenças pressupóem que os sentimentos de um indivíduo influenciam, para bem ou para mal, outros indivíduos. Evidentemente, como tão bem sugerira Gluckman 12 (1973), esses sentimentos são socialmente dirigidos e refletem necessariamente a estrutura social em que ocorrem (Queiroz28, 1980).

Finalmente, a crença de que a desarmonia do individuo com ele mesmo e com agentes sobrenaturais traz doenças está presente nas não menos difundidas crenças em "susto", vontade insatisfeita ou ainda em espíritos interferindo maleficamente nos negócios humanos. Como no caso anterior, essas crenças só fazem sentido quando em operação num determinado contexto social.

$\mathrm{Na}$ África, a noção de que doenças refletem um desequilíbrio social chegou a um grau de grande sofisticação, como nos mostram tanto Evans-Pritchard 10 (1937) como Tumer32 (1967). A obra de Evans-Pritchard10 sobre os Azande é clássica. Ele mostra que para esse povo (e para muitos outros da África como nos têm mostrado etnografias recentes), toda a doença, assim como toda a má-sorte individual provém de um feitiço feito por uma outra pessoa. O objetivo desse autor é mostrar que, longe de ser uma crença ilógica própria de uma mentalidade primitiva, esta crença reflete uma estrutura de poder dentro da sociedade. A acusação de feitiçaria não é gratuíta e obedece a uma lógica onde conflitos socialmente estruturados se expressam e se reconciliam através de uma complexa interação social.

Turner 32 (1967) leva adiante as idéias estabele. cidas por Evans-Pritchard10 ao mostrar que o médico Ndembu encara o seu papel muito menos concentrado no paciente individual do que voltado para remediar os males do grupo corporado. Em suas palavras, "a doença de um paciente é princi- 
palmente um sinal de que 'alguma coisa está podre' no grupo corporado" (Turner32, $1967: 392$ ). Turner observa nessa obra que o paciente não melhorará enquanto as tensões e agressőes nas inter-relações grupais não tiverem sido expostas à luz e ao tratamento ritual. Nesse sentido, o papel do médico Ndembu é se deixar sensibilizar pelas correntes sociais de sentimentos conflituosos e pelas disputas interpessoais e sociais nas quais elas se expressam, e canalizá-las num sentido positivo. Assim, "as energias cruas do conflito são domesticadas a serviço da ordem social" (Turner32 1967: 392).

Muitos estudos têm mostrado a eficácia terapêutica de curandeiros populares manipulando os símbolos partilhados por seus clientes. Magna$\mathrm{ni} 22$ (1979), em particular, sugere que rituais como os da Umbanda, porque fazem sentido dentro do meio social em que se manifestam, e porque oferecem uma interpretação coerente às ambiguidades e paradoxos da experiência humana, têm uma inegável eficácia terapêutica.

No entanto, devemos nos resguardar de romantizar a verdade contida nas medicinas "primitivas" $\mathrm{e}$ "populares" deixando de ver que elas não são capazes de erradicar o baixíssimo nivel de saúde das populações a que servem. Para isso, todo um quadro de má-nutrição, pobreza e precário controle am. biental deveria ser eliminado.

$\mathrm{O}$ aspecto psicossomático e social da cura de doenças foi abordado por Lèvi-Strauss 19 (1970) no capitulo "O feiticeiro e sua magia". Ao utilizar o conceito de "eficácia simbólica", esse autor mostra que a manipulação ritual de certos símbolos socialmente significativos tem o poder de curar ou produzir enfermos. No caso de doenças provocadas por rituais, Lèvi-Strauss lembra a pesquisa de Cannon ${ }^{3}$ (1942). Esta pesquisa demonstrou que feitiços e conjụras publicamente lançados contra um individuo podem causar doenças e mesmo a morte desse indivíduo em sociedades que acreditam nesse poder. Isso porque, assim marcado, ele seria excluído de seu meio social e "a integridade física não resiste à dissolução da personalidade social" (Lévi-Strauss ${ }^{19}$, $1970: 184)$.

No caso da cura, o ritual concentra uma conside. rável atenção social no paciente, promovendo um reajuste nos seus papéis de modo a produzir uma melhor adaptação e, conseqüentemente, uma melhora no seu estado de saúde. Ao mesmo tempo que o ritual promove a cura, numa relação simbiótica, a cura se torna uma forte instância na qual a cultura se legitima e se sustenta.

Nesse capítulo, Lèvi-Strauss ${ }^{19}$ conta a estória anteriormente coletada por Boas de um índio do Noroeste Americano chamado Quesalid que havia se tornado um grande curandeiro. $\mathrm{Na}$ descrição de sua carreira, fica claro o aspecto social da cura, que depende basicamente da crença do curandeiro em suas técnicas, da crença do paciente no curandeiro e. finalmente, da crença do meio social do paciente no sistema de cura empregado pelo curandeiro. Esses três aspectos devem necessariamente ocorrer conjuntamente para que a cura possa ocorrer. Como salienta Lèvi-Strauss ${ }^{19}$, Quesalid não era um grande curandeiro porque curava seus pacientes, mas curava seus pacientes porque era um grande curandeiro.

Wright33 (1979), estudando a medicina na Inglaterra no século XVII, conclui que a medicina científica ocidental se tornou hegemônica no fim desse século não porque seu conhecimen to era mais válido do que a medicina astrológica que a precedeu, e menos ainda porque a sua eficácia terapêutica era maior. Na verdade, a única explicação para o sucesso histórico dessa forma de medicina se encontra em sua compatibilidade cultural com o novo modo de produção capitalista.

Wright 33 é bastante convincente ao mostrar que o desenvolvimento da medicina não pode ser visto em termos de uma resposta técnica a uma necessidade pré-existente, uma vez que o sentido de necessidade é dependente das forças materiais e culturais do tempo. Assim, a medicina, diante da revolução mercantil do século XVII, da valorização do lucro e do domínio da natureza se torna intervencionista (em oposição às noções então prevalentes de harmonia e equilíbrio), enfatiza uma relação individual e solitária entre médico e paciente (em congruência com a ideologia individualista do tempo) e acentua a etiologia individualista da doença (compatibilidade com o puritanismo então vigente).

Portanto, se a medicina científica ocidental se impôs não por causa de sua maior eficácia, ela se torna eficaz depois de ter sido imposta pelas forças políticas, sociais e ideológicas do seu tempo. Não estamos, portanto, longe da fórmula de Lèvi-Strauss 19 a respeito do índio Quesalid.

A Farmacologia tem contribuido para desestabilizar o mito positivista através de suas investigações com placebos. Placebos são substâncias inativas que, no entanto, agem farmacologicamente movidas pelas expectativas do paciente. Numerosas pesquisas têm comprovado que o efeito placebo pode afetar qualquer órgão ou sistema do corpo humano, provendo alivio a uma grande variedade de condições e até mesmo causando efeitos colaterais e dependència. $O$ efeito placebo depende de elementos culturais e sociais, e é componente essencial em todas as formas de cura.

$O$ recurso à terapia placebo é amplamente usado pelos médicos ocidentais, como nos mostra Comaroff4 (1976). O artigo de Comaroff é particularmente interessante na medida em que a terapia placebo é observada sob a perspectiva do médico, cuja 
dependência dela é vista como um fator indispensável para a preservação do seu saber num plano glo. bal e sistemático diante da sua incerteza num plano cotidiano individual.

Portanto, a terapia placebo é efetiva tanto para os clientes (porque expectativas positivas são componentes essenciais para a cura) como para os médicos (porque tal terapia permite que eles desempenhem a sua função com maior confiança).

Helman ${ }^{13}$ (1984) realiza importante análise sobre as principais pesquisas realizadas sobre o efeito placebo, e uma de suas mais interessantes conclusōes é atribuir a ele o fato de que o índice de eficácia de muitas drogas e tratamentos, depois de atingirem de 70 a $90 \%$, começam a cair paulatinamente até chegar de 30 a $40 \%$, que nada mais é do que a média avaliada para a ação placebo ce qualquer droga ou terapia. Helman interpreta isso pelo entusiasmo e a expectativa de médicos ou pesquisadores que instigam efeito placebo em agentes experimentais. Mais tarde, pesquisas realizadas por investigadores mais céticos revelam grande diminuição da eficácia. Daí a necessidade da medicina estar sempre inovando.

\section{CONCLUSÃO}

A medicina ocidental moderna desenvolveu-se mudando uma cosmologia voltada para a pessoa hu. mana para uma cosmologia voltada para o objeto. Tem havido ganhos e perdas nesse processo. Por um lado, houve aperfeiçoamento de técnicas terapêuticas e o desenvolvimento de um corpo consistente de conhecimentos com a concomitante redução da controvérsia sobre a natureza da doença e de seu tratamento; por outro lado, a medicina perdeu sua visão unificadora do paciente em particular e da vida em geral como agentes que resultam, na saúde e na doença, de fatores ambientais, sociais e econômicos, além dos fatores biológicos. A medicina ocidental moderna necessita recuperar, na sua prática, essa dimensão, porque ela é teoricamente mais rica, equilibrada e próxima das causas reais que envolvem a saúde e a doença em seres humanos. Para isso ela necessita reordenar o enorme conjunto de conhecimentos e tecnologias até hoje acumulados, como solução para a sua crise e em altemativa ao seu paradigma mecanicista dominante.
A recuperação dessa dimensão significa permitir à medicina um desempenho com maior autonomia das forças e interesse políticos, econômicos e ideo. lógicos da sociedade; significa também postular a necessidade de encontrar instâncias mediadoras que lhe possibilitem manter uma certa distância das in. fluências sociais mais imediatas. Essas influências ocorrem no plano econômico na medida em que, por exemplo, indústrias farmacêuticas. de equipamentos hospitalares ou ainda as mantenedoras de hospitais privados influenciam a prática médica e direcionam linhas de investigação e de produção de conhecimentos. Elas se manifestam no plano político na medida em que, por exemplo, interesses de manutenção do poder da profissão médica, isolados ou em conjunção com interesses de classe, prevalecem organizando tanto a prática como o saber médicos no sentido de manutenção do "status quo". Elas ocorrem, finalmente, no plano ideológico na medida em que o mito da excelência tecnológica, ou seja, a crença de que problemas humanos podem quase sempre ser resolvidos por uma solução técnica se reproduz na prática e no saber médicos em compatibilidade com o "ethos" da sociedade industrial capitalista.

Nessa perspectiva, articular as dimensões biológicas com as sociológicas na construção social do saber e da prática médicas implica adotar soluçōes compatíveis com as causas dos problemas de saúde humanos. Essa postura está, evidentemente, relacionada com a construção de uma medicina mais influenciada pelo pensamento e metodologia científicas e menos influenciada pelas forças primárias que organizam a sociedade capitalista.

Evidentemente, essa reorientação deve começar a ocorrer no campo teórico e científico, ou seja, no campo das idéias para, pouco a pouco, ao minar a resistência dos interesses sócio-econômicos comprometidos com o capital, encontrar condições institucionais para transformar as idéias em práticas. Essa postura é perfeitamente coerente com a interpretação marxista de Gransci, para quem a revolução no ocidente deve iniciar-se no campo da cultura. Nesse sentido, é possivel criticar a concepção marxista ortodoxa de que não se pode mudar a medicina (uma área da super-estrutura social) sem mudar as bases econômicas da sociedade (uma área da infra-estru. tura social). 
QUEIROZ, M. de S. [The "mechanistic" paradigm of modern western medicine: an anthropological perspective ] . Rev.Saúde públ., S.Paulo, 20:309-17, 1986.

ABSTRACT: The dominant "mechanistic" paradigm of modern western medicine was analysed from an anthropological point of view. Some critical comments on the positivistic posture which underlies this paradigm were made, as well as a historical overview of how it has developed (dominating medical perception of health, disease and therapeutics) up to its present crisis. An analysis of some "primitive" and "popular" medical systems showing how they incorporated social elements into strategies of treatment and cure was also made. It was emphasised that modern western medicine needs to recover its social and cultural dimensions in order to overcome its present crisis. In this sense, looking to history as well as to "primitive" and "popular" medical systems has the aim of contributing to this search.

UNITERMS: Anthropology, medical. Medicine, traditional. History of medicine.

\section{REFERENCIAS BIBLIOGRAFFICAS}

1. BACHA, C.S. The emergence of finance capitalism in Brazil. Manchester, 1979. [ Ph.D. Thesis-University of Manchester ].

2. BERLINER, H. Medical modes of production. In: Wright, P. \& Treacher, A., eds. The problem of medical knowledge. Edinburg, Edinburg University Press, 1982. p. 162-73.

3. CANNON, W.B. "Voodoo" death. Amer.Anthropol., $44: 169-81,1942$.

4. COMAROFF, J. A bitter pill to swallow: placebo therapy and general practice. Sociol.Rev., $76: 247-59$, 1976.

5. CONTI, L. Estrutura social y medicina. In: Medicina $y$ socieded. Barcelona, Libros de Confrontacion, - 1972. p. 287-310.

6. DONNANGELO, M.C.F. Medicina e sociedade. São Paulo, Pioneira, 1975.

7. DOYAL, L. The political economy of health. London, Pluto Press, 1979.

8. DUBOS, R.J. Man adapting. New Haven, Yale University Press, 1965.

9. EHRENREICH, J. Introduction: the cultural crisis of modern medicine. In: Ehrenreich, J., ed. The cultural crises of modern medicine. New York, Momphley Review Press, 1978. p. 1-38.

10. EVANS-PRITCHARD, E.E. Witchcraft, oracles and magic among the Azande. Oxford, Claredon Press, 1937.

11. FLEXNER, A. Medical education in the United States and Canada. New York, Carnegie Foundation for Advancement of Teaching, 1910. (Bulletin n. 4).

12. GLUCKMAN, M. Custom and conflict in Africa. Oxford, Basil Blackwell, 1973.

13. HELMAN, C. Culture, health and illness. Bristol, Wright PSG, 1984.

14. ILliCH, I. A expropriação da saúde. Rio de Janeiro, Nova Fronteira, 1975.

15. JEWSON, N.D. The disappearance of the sick-man from medical cosmology. Sociology, $10: 225-44$, 1976.

16. KUHN, T.S. A estrutura das revoluçōes cientificas. São Paulo, Perspectiva, 1975.

17. LAKATOS, I. \& MUSGRAVE, A. Criticism and growth of knowledge. Cambridge, Cambridge University Press, 1970.
18. LANDMAN, J. Medicina nðo é saúde. Rio de Janeiro, Nova Fronteira, 1983.

19. LEVI-STRAUSS, C. Antropologia estrutural. Rio de Janeiro, Tempo Brasileiro, 1970.

20. LIVINGSTONE, Sir.R.W., ed. Plato: selected passages. Oxford, Oxford University Press, 1940.

21. McKEOWN, T. The role of medicine. Oxford, Basil Blackwell, 1979.

22. MAGNANI, J.G.C. Doença e cura na religião umbandista. Campinas, Departamento de Ciências Sociais da UNICAMP, 1979. [Mimeografado]

23. NAVARRO, V. Medicine under capitalism. New York, Prodist, 1976.

24. NAVARRO, V. Social security and medicine in the USSR. New York, Lexington Books, 1977.

25. POPPER, Sir $\mathbf{K}$. Normal science and its dangers. In: Lakatos, I. \& Musgrave, A., eds. Criticism and the growth of knowledge. Cambridge, Cambridge University Press, 1970. p. 141-64.

26. POSSAS, C. Saúde e trabalho. Rio de Janeiro, Graal, 1981.

27. POWLES, J. On the limitation of modern medicine. In: Mechanic, $\mathrm{D}_{\text {, }}$ ed. Readings in medical sociology. New York, The Free Press, 1980. p. 18-45.

28. QUEIROZ, M.S. Feitiço, mau olhado e susto: seus tratamentos e prevençōes na aldeia de Icapara. Relig. e Soc., (5) : 131-60, 1980.

29. QUEIROZ, M.S. Hot and cold: a fundamental system of classification to the traditional medicine in Iguape. Manchester, University of Manchester Press, 1982. (Occasional Paper, 8).

30. QUEIROZ, M.S. Hot and cold classification in traditional Iguape medicine. Ethnology, 23 (1): 63-72, 1984.

31. SARTRE, J.P. Questđo de método. São Paulo, Difusão Européia do Livro, 1967.

32. TURNER, V.W. The ritual process. London, Routledge \& Kegan Paul, 1967.

33. WRIGHT, P.W.G. Study in the legitimation of knowledge: the "sucess" of medicine and the "failure" of astrology. Sociol. Rev. Monogr., 27 : 85-99, 1979.

Recebido para publicação em 26/02/1986.

Aprovado para publicação em 09/06/1986. 